\title{
The role of particulate matter in offices for urban air quality management
}

\author{
M. Ragazzi, E. C. Rada, S. Zanoni \& G. Andreottola \\ Department of Civil, Environmental and Mechanical Engineering, \\ University of Trento, Italy
}

\begin{abstract}
The particulate matter (PM) in the air of office environments plays an important role in the daily human exposure in urban areas. The present paper reports a few measurements in order to integrate the knowledge of the sector concerning pollution in offices. The parameter analysed is PM, referred to in three fractions of interest, depending on their dimensions. Some considerations are reported in order to set or confirm specific criteria for the correct management of office air quality.
\end{abstract}

Keywords: air, office, particulate matter, quality, urban.

\section{Introduction}

In the last three decades, atmospheric particulate matter (PM) has been at the core of a lot of research, with a growing interest from the scientific community and public opinion dealing with the concept of the sustainable city [1-5]. Several epidemiological studies have claimed that PM has strong effects on human health; a high correlation between air pollution and irritation to the respiratory tract, pulmonary and cardiovascular diseases and visual disturbances has been underlined; in addition, the long-term exposure to PM increases the chance of developing cancerous diseases [6]. PM size plays an important role in human-air interaction: fine particles (FP, diameter $<2.5 \mu \mathrm{m}$ ) and ultrafine particles (UFP, diameter $<0.1 \mu \mathrm{m}$ ) are more harmful [7-8]. In fact, FP can reach undisturbed the pulmonary alveoli through trachea and bronchi [9-10].

At the international level, the strong attention to the atmospheric pollution has led to the adoption of a series of laws aimed at the control of emissions from industrial and transport sectors. In Italy, the Legislative Decree 155/2010, through 
transposition of the European Directive 2008/50/EC, fixes the outdoor annual average concentrations ( $40 \mu \mathrm{g} / \mathrm{m}^{3}$ for $\mathrm{PM}_{10}$ and $25 \mu \mathrm{g} / \mathrm{m}^{3}$ for $\left.\mathrm{PM}_{2.5}\right)$, the maximum outdoor 24 hours-average concentrations allowed for $\mathrm{PM}_{10}\left(50 \mu \mathrm{g} / \mathrm{m}^{3}\right)$ and the number of days exceeding (35). This approach will be critically analysed in the discussion section of the present paper in order to point out some improvements that can be taken into account in underestimated cases of human exposure in offices. More in general, quantification of emissions from indoor sources is very important for the assessment of the total human exposure to particles taking into account that at European level, the majority of the population spends up to $80 \%$ of their day in indoor environments [11].

Wallace and Ott [12] stated that indoor sources provide about $47 \%$ of total daily ultrafine particulate (UFP) exposure. The main sources of air pollution are human activities, such as cooking, domestic heating, cleaning, smoking; even just walking can increase PM levels in the house through re-suspension phenomenon $[11,13,14]$. In addition to the monitoring of selected workplaces [15], recent studies focused on specific indoor environments as houses, pizzerias, cafeteria, hospitals, schools, churches and tunnels [16-19]. It is desirable to pay particular attention to specific spaces: the offices. Electronic equipment (printers, photocopiers, fax), paper residues, clogged filters of air conditioning system, transit of workers may lead a rise in PM concentrations up to the emergence of headaches, eye irritations and rhinitis, if exposure is prolonged [20]. Some sampling carried out in computer rooms, offices and libraries have shown that indoor PM levels are often higher than outdoor and non-compliant with regulations [21].

In Italy, a national legislation for indoor environments has not been defined yet. The international guidelines (issue in United States, Canada, Netherlands, Finland, Norway) can be taken as a reference, although it is clear that lack a common and shared approach. The American Standard ASHRAE [22] gives a further contribution to the field with the advantage of indicating precise values of concentrations: $\mathrm{PM}_{2.5}$ is set to $15 \mu \mathrm{g} / \mathrm{m}^{3}$ (annual exposure) and $35 \mu \mathrm{g} / \mathrm{m}^{3}$ (daily exposure), whereas limit for $\mathrm{PM}_{10}$ are $50 \mu \mathrm{g} / \mathrm{m}^{3}$ (annual exposure) and $150 \mu \mathrm{g} / \mathrm{m}^{3}$ (daily exposure).

The aim of this study is to monitor the human exposure to a range of particle sizes as $\mathrm{PM}_{10}, \mathrm{PM}_{2.5}$ and $\mathrm{PM}_{1}$ and to evaluate the indoor air quality (IAQ) in three different types of office. That in order to expand the already existing literature data on indoor concentrations of PM. Results are discussed concerning some criticalities referred to not optimised outdoor and indoor emissions (industrial activities with diffused emissions; cleaning activities causing re-suspension of $\mathrm{PM})$.

\section{Materials and methods}

The instrument used for PM measurements is the GRIMM analyzer 1.108 [23]. This portable dust aerosol spectrometer allows continuous measurement of airborne particles and their counting into 16 granulometric classes from 0.3 to 20 $\mu \mathrm{m}$. 
The tool is based on the principle of the light scattering of single particle hit by a laser beam. The air is drawn into the instrument by a volume-controlled pump at a rate of 1.2 liters/minute and goes in the measuring cell, where, after the hit with particles, the scattering light is deviated to a mirror and, at last, to the detector. The pulse and the intensity of light are fingerprints able to evaluate the number and the size of each single particle. Finally, the sample is collected onto a $47-\mathrm{mm}$ filter, so any gravimetric analysis is possible.

The data are available in time intervals between 6 and 60 seconds and, in this paper, the $\mathrm{PM}_{10}, \mathrm{PM}_{2.5}$ and $\mathrm{PM}_{1.0}$ values are taken into account, by now become the actual reference classes for World Health Organization (WHO). Even though, a current regulation does not recognize this method as official (they suggest adopting gravimetric methods), the GRIMM analyzer is able to provide a good overview about IAQ of the environments object to study.

The levels of PM inside the offices were monitored in three different situations. In the first case, the offices are located in a service company headquarter (OFF1) and they are separated to outdoor by a reception room. This building consists of several types of room; in each of them the measurements of PM were carried out every 6 seconds in an afternoon at the end of a workday (only five employees were in the building). In the open space room (1A), $16.50 \mathrm{~m}$ long and $7.30 \mathrm{~m}$ wide, four workstations and two photocopiers (only one was working) were present; then the instrument was placed on a shelf in the center of the space at a height of $1.15 \mathrm{~m}$. Another test was performed in a smaller office (1B) with a one workstation and one laser printer, external to the main room and independent from the others. It measures $4.20 \mathrm{~m} \times 3.10 \mathrm{~m}$ and the instrument was placed at a height of $0.9 \mathrm{~m}$. In the same office, another concentration curve of $\mathrm{PM}$ was recorded to evaluate the effects of the air conditioning system (1C), consisting of vertical fun coil units distributed at the edge of the floor. The instrument was fixed at $1.25 \mathrm{~m}$ height oriented towards the cold output airflow. Finally, a particular indoor environment as reception room (1D) was investigated with the instrument placed at a height of $1.45 \mathrm{~m}$ : air quality of the small room $(4.90 \mathrm{~m} \times 3.10 \mathrm{~m})$ was probably affected by the near outside parking and the frequent transit of workers.

For the second campaign of measurements, a building (OFF2) representing a typical situation for small-medium companies was chosen: the analyzed office is closer connected with a workshop. In this case, the office has two workstations with personal computer and one shared printer and its extension is about $11.60 \mathrm{~m}$ $\mathrm{x} 4.90 \mathrm{~m}$. The company at issue is a metallic carpentry, so as the frequent welding, painting and grinding processes in the workshop may contribute to a worsening of IAQ in the entire building. All measurements were carried out in the office under investigation, with time intervals of 6 seconds. The instrument was fixed on a bracket high $1.65 \mathrm{~m}$ at the center of the room. The first test (2A) simulated the case when two employees were doing their daily activities in the office whereas the connecting door to the workshop was closed. The second test (2B) investigated the variations in PM concentrations after a situation that often occurs in the carpentry: the opening of the door between office and workshop and the subsequent transfer of workers from one area to another. At last, the effects of the air conditioning system $(2 \mathrm{C})$ were monitored, as for the first building. 
Finally, taking into account the recent tendency to place all electronic devices in a dedicated room, it was analyzed a printers room (OFF3) inside a public library. In this room $(3.30 \mathrm{~m} \times 2.70 \mathrm{~m})$, four printers are present, the instrument was placed at a height of $0.8 \mathrm{~m}$ and the data were taken every 6 seconds. The first test (3A) was done in the late morning when all the printers were running and the area was crowded, instead in the second test (3B), carried out four hours later, only one printer was in use.

\section{Results and discussions}

The results of the tests are summarized in Table 1. In 1A (Figure 1) and 1B tests; results have shown that general indoor air quality was good: in every monitored area the concentrations of PM were lower than thresholds values suggested by ASHRAE Standard.

PM levels were similar in the open space room and in the independent office, probably due to poor re-suspension of dust because of the low presence of people in the building during the day. This phenomenon is clearly visible in the test $1 \mathrm{D}$ (Figure 2): increments of $\mathrm{PM}_{10}$ concentrations were recorded in correspondence of the transit of workers through the reception. The presence of fitted carpet definitely gets worse indoor air quality, which may reach danger levels in the morning and in the late afternoon at the time of entry or exit of employers.

Table 1: $\quad$ Maximum and average concentrations of PM10, PM2.5, PM1 for all tests.

\begin{tabular}{|c|c|c|c|c|c|c|c|}
\hline & \multicolumn{3}{|c|}{$\operatorname{Maximum}\left(\mu \mathrm{g} / \mathrm{m}^{3}\right)$} & \multicolumn{3}{|c|}{ Average $\left(\mu \mathrm{g} / \mathrm{m}^{3}\right)$} \\
\hline & & $\mathbf{P M}_{10}$ & $\mathbf{P M}_{2.5}$ & $\mathbf{P M}_{1.0}$ & $\mathbf{P M}_{10}$ & $\mathbf{P M}_{2.5}$ & $\mathbf{P M}_{1.0}$ \\
\hline \multirow{4}{*}{ OFF1 } & $\mathbf{1 A}$ (open space) & 14.5 & 10.1 & 9.1 & 11.3 & 9.5 & 8.8 \\
\hline & 1B (independent office) & 24.6 & 10.1 & 8.5 & 13 & 9.1 & 8.1 \\
\hline & 1C (A/C system) & 35.1 & 9.4 & 8.4 & 11.7 & 9 & 8.2 \\
\hline & $1 D$ (reception) & 20.2 & 9.4 & 8.2 & 14.8 & 8.9 & 7.9 \\
\hline \multirow{3}{*}{ OFF2 } & $\mathbf{2 A}($ door closed $)$ & 52.1 & 14.9 & 10.7 & 28.5 & 13.4 & 10.2 \\
\hline & $\mathbf{2 B}$ (door open) & 51.9 & 16.9 & 12.3 & 29.2 & 15.6 & 11.1 \\
\hline & 2C (A/C system) & 30.7 & 14.5 & 10.7 & 23.5 & 13 & 10.2 \\
\hline \multirow{2}{*}{ OFF3 } & 3A (morning) & 33 & 4.9 & 3.6 & 17.1 & 4 & 3.2 \\
\hline & 3B (afternoon) & 24.3 & 6 & 4.8 & 16.6 & 5.2 & 4.4 \\
\hline
\end{tabular}




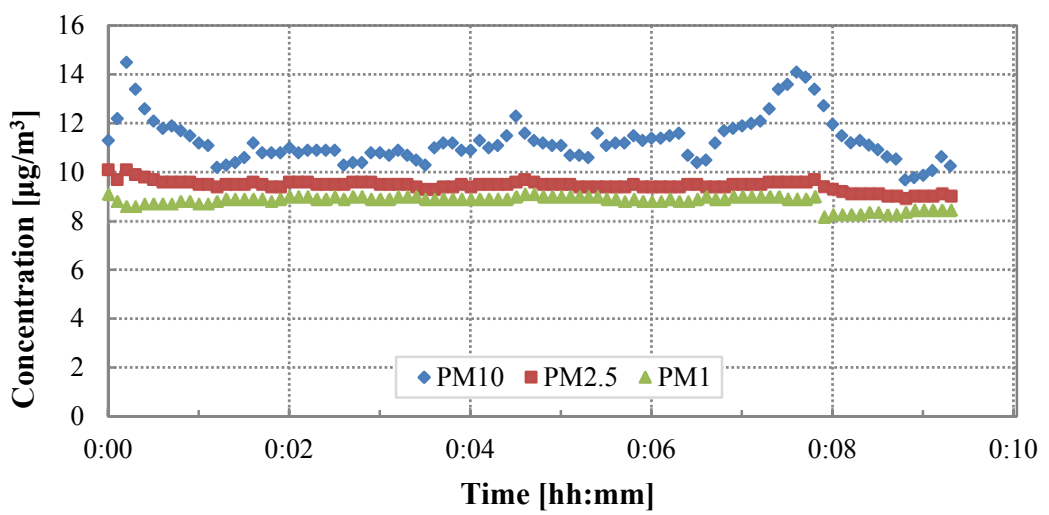

Figure 1: Concentration profiles of $\mathrm{PM}_{10}, \mathrm{PM}_{2.5}, \mathrm{PM}_{1}$ during the test $1 \mathrm{~A}$.

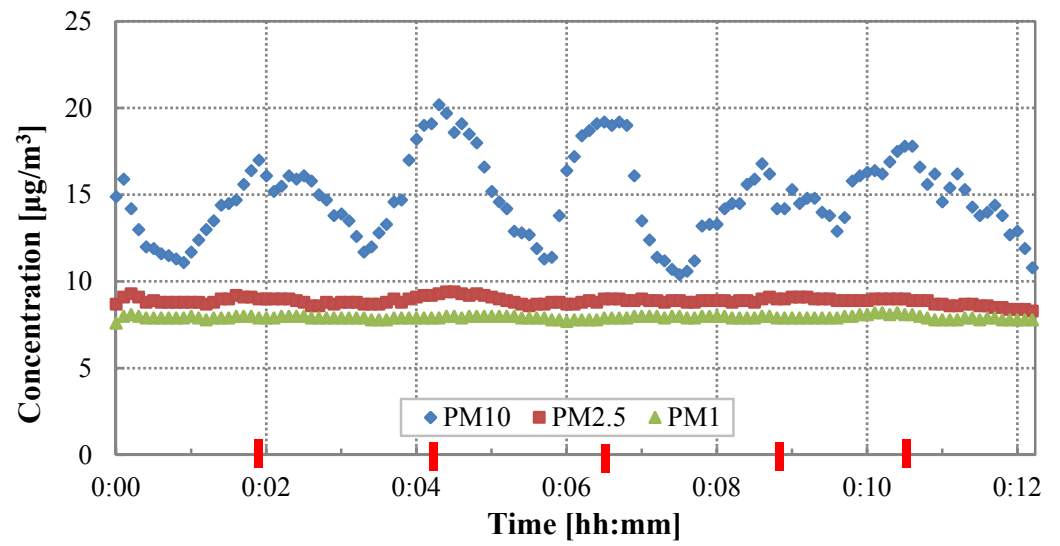

Figure 2: $\quad$ Concentration profiles of PM10, PM2.5, PM1 during the test 1D (red marks indicate the transit of workers through the room).

The air conditioning system was a help in maintaining high standards for air, in fact, the low levels of PM in the output flux of fan coil unit, as seen in test 1C, were a signal that filters were in good condition and they were able to retain particles.

The higher values of PM were registered inside OFF2; we can state that the adjacent workshop negatively affects the state of air in the office causing a rise in levels of PM (Figure 3). To confirm this, in the test 2B (Figure 4) it should be noted the peak of PM concentrations when the door was open during a grinding process, known in releasing large amount of particulate in the air.

The air conditioning system led no improvements to air quality, probably due to clogged filters of the old fun coil units. 


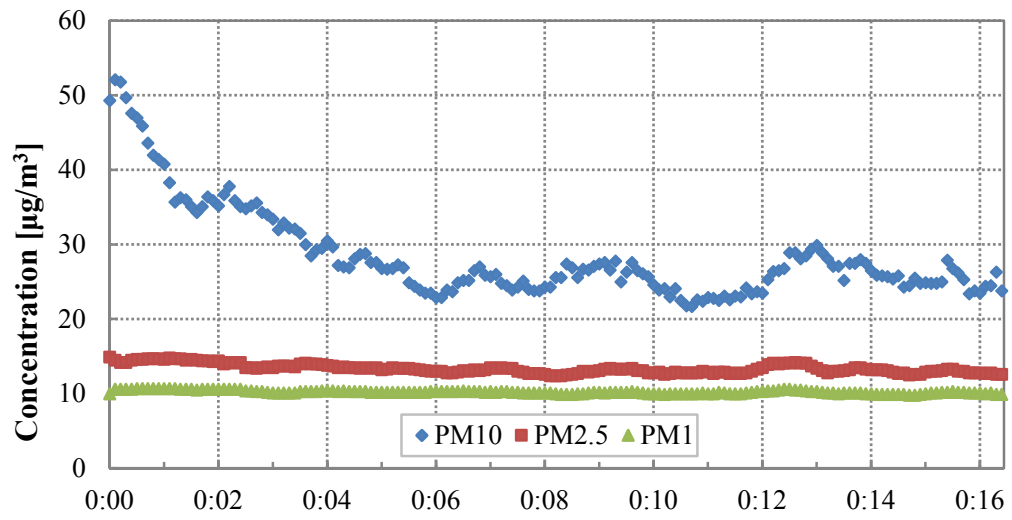

Time [hh:mm]

Figure 3: Concentration profiles of $\mathrm{PM}_{10}, \mathrm{PM}_{2.5}, \mathrm{PM}_{1}$ during the test $2 \mathrm{~A}$.

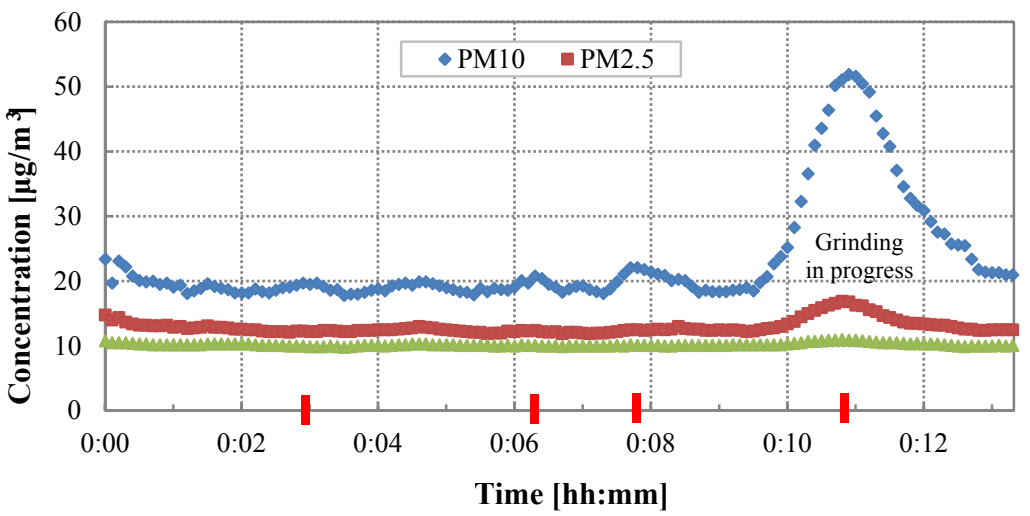

Figure 4: Concentration profiles of PM10, PM2.5, PM1 during the test 2B (red marks indicate the openings of the door connecting the office with workshop).

In test 3A (Figure 5), the time when study room was left to get into the printers room was clearly indicated by the step of $\mathrm{PM}_{2.5}$ and $\mathrm{PM}_{1}$ concentrations. This implies the entry into an environment rich of particulate derived from toner dust and paper residues. The oscillating values of $\mathrm{PM}_{10}$ were due to movements of the occupants of the room, which cause the re-suspension of coarse particles.

As seen in Table 1, during the test 3B the room was less crowded and, in fact, $\mathrm{PM}_{10}$ was lower than morning and more stable. $\mathrm{PM}_{2.5}$ and $\mathrm{PM}_{1}$ were increased compared to the test $3 \mathrm{~A}$. This underlines that the removal velocity by deposition is higher for coarse particles and the risk from the presence of fine particles does not decrease with the end of printing operations. 


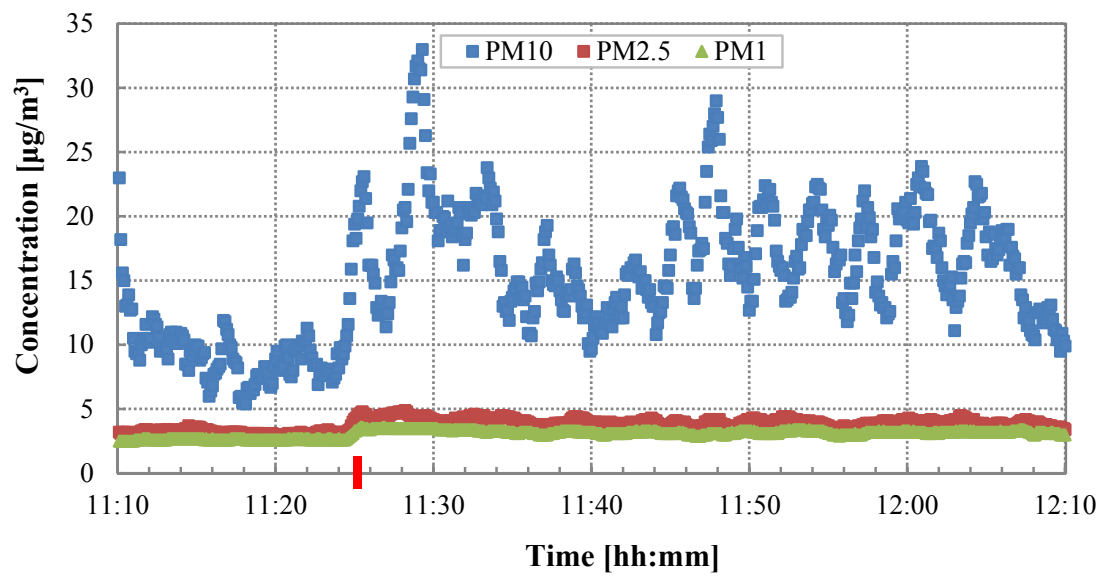

Figure 5: $\quad$ Concentration profiles of PM10, PM2.5, PM1 during the test 3A (red mark indicate the entry into printers room).

The above reported results can be discussed also from a wider point of view. Indeed some recent literature pointed out that some industrial activities, sometimes located also in urban context, can be responsible of diffused emissions that can significantly affect the air quality in the surroundings of the plants generating them. What must be underlined is that the above mentioned impact can affect also the air quality in the offices present in those companies (not only PM). For instance, this criticality can be found in the following cases:

- Aerobic biological mechanical treatment of waste when the process air is treated by an open biofilter [24];

- Anaerobic digestion of organic fractions when the stack characteristics are not well designed [25];

- Steel making plants showing secondary and diffused emissions as a characteristics of the design of the process [26].

In the above-mentioned cases an important contribution to the mitigation of the indoor impact could come from the optimization of the cleaning activities in the offices. To this concern it must be pointed out that the sector does not have specific guidelines to guarantee quantitative results.

\section{Conclusions}

The IAQ of the offices could be adversely affected by the crowding of people in small areas and the use of electronic devices responsible for the release of FP into air, as seen in the case OFF3. The removal velocity by deposition for FP is lower than for coarse particle. This means that concentrations of FP remain high even at the end of the activities that generated it. For these reasons, the planning solution of concentrate all electronic equipments in a separated room with dedicated air aspiration has proven to be very effective and to recommend in the future. To 
improve the IAQ in the office, the main rule to follow is a proper design of the spaces, so as to avoid the offices to bordering areas with large emissions of pollutants. In the OFF2, the workshop worsened the IAQ of the entire building causing high concentrations of PM in the next office. In this specific case, a solution to limit the impact might be to build a separator hallway with a second door at the end, so as to increase the isolation of the two environments. In addition, the correct maintenance of the air conditioning systems is a help to preserve not hazardous for human health concentrations of PM in the office because the cooling units are equipped with filters capable of retaining particles. The test 1D has highlighted the negative role of fitted carpet: it captures the dust and it releases them at a later time during the transit of people. From a wider point of view, two aspects should be taken into account with a deeper attention, considering the role of offices in the daily exposure to PM for a few persons: diffused emissions from industrial activities must be avoided as they can contribute significantly to the background PM level in the offices of the company responsible for those emissions; cleaning activities for offices should be optimized also adopting specific guide lines to prevent re-suspension.

\section{References}

[1] Vecchi R., Marcazzan G., Valli G., Ceriani M., Antoniazzi C., The role of atmospheric dispersion in the seasonal variation of $\mathrm{PM}_{1}$ and $\mathrm{PM}_{2.5}$ concentration and composition in the urban area of Milan (Italy). Atmospheric Environment, 38(27), pp. 4437-4446, 2004.

[2] Ionescu G., Apostol T., Rada E.C., Ragazzi M., Torretta V., Critical analysis of strategies for PM reduction in urban areas. UPB Scientific Bulletin, series D, 75(2), pp. 175-186, 2013.

[3] Torretta V., Raboni M., Copelli S., Rada E.C., Ragazzi M., Ionescu G., Apostol T., Badea A., Application of strategies for particulate matter reduction in urban areas: an Italian case, UPB Scientific Bulletin, 75(4), serie D, pp. 221-228, 2013.

[4] Martuzzi M., Galassi C., Ostro B., Forastiere F., Bertollini R., Health impact assessment of air pollution in the eight major Italian cities, WHO Regional Office for Europe, Copenhagen, 2002.

[5] Van Dingen R., Raes F., Putaud J.P., Baltensperger U., Charron A., Facchini M.C., Decesari S., Fuzzi S., Gehrig R., Hansson H.C., Harrison R.M., Higlig C., Jones A.M., Laj P., Lorbeer G., Maenhaut W., Palmgren F., Querol X., Rodriguez S., Schneider J., Ten Brink H., Weingartner E., Wiedensohler A., Wahlin P., A European aerosol phenomenology-1: physical characteristics of particulate matter at kerbside, urban, rural and background sites in Europe, Atmospheric Environment, 38(16), pp. 2561-2577, 2002.

[6] Makri A., Stilianakis N., Vulnerability to air pollution health effects, International Journal of Hygiene and Environmental Health, 211(3-4), pp. 326-336, 2008. 
[7] Aarnio P, Martikainen J, Hussein T, Valkama I, Vehkamäki H, Sogacheva L, Härkönen J, Karppinen A, Koskentalo T, Kukkonen J, Kulmala M, Analysis and evaluation of selected PM10 pollution episodes in the Helsinki Metropolitan Area in 2002, Atmospheric Environment 42, pp. 3992-4005, 2008.

[8] Pedata P., Garzillo E. M., Sannolo N., Particolato ultrafine ed effetti sull'organismo: revisione della letteratura, Giornale Italiano di Medicina del Lavoro ed Ergonomia, 32(1), pp. 23-31, 2010.

[9] Taner S., Pekey B., Pekey H., Fine particulate matter in the indoor air of barbeque restaurants: Elemental compositions, sources and health risks, Science of the Total Environment, 454-455(1), pp. 79-97, 2013.

[10] Massey D., Kulshrestha A., Masih J., Taneja A., Seasonal trends of PM10, PM5.0,PM2.5 \& PM1.0 in indoor and outdoor environments of residential homes located in North-Central India, Building and Environment, 47, pp. 223-231, 2011.

[11] Rada E.C., Ragazzi M., Antolini D., Malloci E., Venturi M., In-door air measurements of PM10 in different conditions, Proceedings of International Symposium on Environmental science and technology, pp. 571-577, 2009.

[12] Wallace L., Ott W., Personal exposure to ultrafine particles, Journal of Exposure Science and Environmental Epidemiology, 21, pp. 20-30, 2011.

[13] Schiavon M., Rada E.C., Ragazzi M., Antolini D., Indoor measurements of particulate matter during beef-steak cooking under different conditions, WIT Transactions on Ecology and the Environment, 173, pp. 255-264, 2013.

[14] Abt E., Suh H.H., Allen G, Koutrakis P., Characterization of indoor particle sources: a study conducted in the metropolitan Boston area, Environmental Health Perspect, 108, pp. 35-44, 2000.

[15] Kousa A., Oglesby L., Koistinen K., Künzli N., Jantunen M., Exposure chain of urban air PM2.5-associations between ambient fixed site, residential outdoor, indoor, workplace and personal exposures in four European cities in the EXPOLIS-study. Atmospheric Environment, 36, pp. 3031-3039, 2002.

[16] Buonanno G., Morawska L., Stabile L., Viola A., Exposure to particle number, surface area and PM concentrations in pizzerias. Atmospheric Environment, 44, pp. 3963-3969, 2010.

[17] Chao C.Y.H., Wan M.P., Cheng E.C.K., Penetration coefficient and deposition rate as a function of particle size in non-smoking naturally ventilated residences, Atmospheric Environment, 37, pp. 4233-41, 2003.

[18] Habil M., Massey D.D., Taneja A., Exposure of children studying in schools of India to PM levels and metal contamination: Sources and their identification, Air Quality, Atmosphere and Health 6(3), pp. 575-587, 2013.

[19] Chuang H.C., Jones T., BéruBé K., Combustion particles emitted during church services: Implications for human respiratory health. Environment International, 40, pp. 137-142, 2012.

[20] Destaillats H., Maddalena R., Singer B., Hodgson A., McKone T., Indoor pollutants emitted by office equipment: A review of reported data and information needs, Atmospheric Environment, 42, pp. 1371-1388, 2008. 
[21] Liu Y, Chen R, Shen X, Mao X, Wintertime indoor air levels of PM10, PM2.5 and PM1 at public places and their contributions to TSP, Environment International 30, pp. 189-197, 2004.

[22] ASHRAE, Ventilation for Acceptable Indoor Air Quality, ANSI/ASHRAE Standard 62.1,2007

[23] GRIMM Aerosol, www.grimm-aerosol.com/en/Indoor-Air Quality/2/2/ index.html

[24] Rada E.C, Ragazzi M., Badea A., MSW bio-drying : design criteria from 10 years research, UPB Scientific Bulletin, 74(3), serie D, pp. 209-216, 2012.

[25] http://www.manuremanagement.cornell.edu/Pages/General_Docs/Events/1 5.Joe.Hower.pdf

[26] Ciuta, S., Schiavon M., Chistè A., Ragazzi M., Rada E.C., Tubino M., Badea A., Apostol T., Role of feedstock transport in the balance of primary PM emissions in two case-studies: RMSW incineration vs. sintering plant, UPB Scientific Bulletin, 74(1), serie D, pp. 211-218, 2012. 